\title{
Bioequivalence Study of Two Valsartan 160 mg Formulations: An Open- Label, Randomised-Sequence, Single-Dose, Two-Way Crossover Study in Healthy Volunteers under Fasting Conditions
}

\author{
Wen Yao Mak ${ }^{1 *}$, Siew Siew Tan ${ }^{2}$, Jia Woei Wong², Siaw Kuen Chin², Ai Boey Lim², Ean Peng Soon², Irene Looi ${ }^{1}$ and Kah Hay Yuen²
}

${ }^{1}$ Clinical Research Centre, Hospital Seberang Jaya, Jalan Tun Hussein Onn, 13700 Seberang Jaya, Pulau Pinang, Malaysia

${ }^{2}$ Hovid Research Sdn Bhd, USM Laboratory Room 024, Kompleks EUREKA, University Sains Malaysia, 11800 USM, Pulau Pinang, Malaysia

\begin{abstract}
The aim of the study was to evaluate the rate and extent of absorption of a local generic valsartan formulation against that of the innovator product (reference formulation) in order to establish bioequivalence between both products. The study was an open-label, randomised-sequence, single-dose, two-way crossover study in 24 healthy volunteers under fasting conditions. The washout period was set at 7 days between the two treatment periods. Blood samples were collected up till 24-hour post dose. Plasma level of valsartan was determined by high performance liquid chromatography with fluorescence detector. Non-compartmental model was used to analyse the pharmacokinetic parameters, which included $T_{\text {max }}, C_{\text {max }}, A \cup C_{0-1}, A U C_{0-\infty}, t_{1 / 2}$ and $k_{e}$. Analysis of variance (ANOVA) was used to analyse values of $C_{m a}, A \cup C_{0,}, A \cup C_{0 \infty}$, and $k_{e}$, while Wilcoxon Signed Rank Test for paired samples was used to analyse $\mathrm{T}_{\text {max }}$. Tolerability of the test formulation was assessed throughout the study. All parameter assessed were found to be within the acceptable limit of $80.00 \%$ to $125.00 \%$. No adverse event was reported. In conclusion, the test formulation was bioequivalent to the reference formulation, based on the rate and extent of absorption of both products.
\end{abstract}

Keywords: Bioequivalence; Generic; Valsartan; Angiotensin receptor blocker; Hypertension

\section{Introduction}

Valsartan is an antagonist to the angiotensin type I receptor (AT1), of which plays an integral role in hypertension [1]. The renin angiotensin aldosterone system (RAAS) produces an effector compound called angiotensin II, where it mediates its effect through the stimulation of AT1 and AT2 receptors. Angiotensin receptor blockers (ARBs) are recommended as alternative treatments to patients who are intolerant to ACE inhibitors and who has suffered acute myocardial infarction with a left ventricular ejection fraction less than $40 \%$, or clinical (or radiological) evidence of heart failure [2].

Valsartan is a non-heterocyclic, potent, and orally active antagonist to the AT1 receptors $\left(\mathrm{IC}_{50}\right.$ of $2.7 \mathrm{nmol} / \mathrm{L}$ on rat aorta) [3]. It is rapidly absorbed after ingestion but has low absolute bioavailability. Administration of valsartan together with food reduces the extent of drug absorption by approximately $50 \%$. Valsartan is highly bound to plasma protein, particularly albumin. It is largely eliminated in faeces, with an average elimination half-life of 6 hours [4]

Malaysia practices a universal healthcare system whereby all citizens' healthcare expenses are largely covered by the Ministry of Health. While the system is beneficial to the public, the consequential financial burden is significant. The Ministry had launched the National Strategic Plan for Non Communicable Diseases in 2010 to combat the increasing disease burden, particularly hypertension $[5,6]$.

ARBs such as valsartan are recommended by clinical practice guidelines to treat hypertension [5]. However the inovator product is relatively expensive to allow optimum use among patients especially those who are economically under privileaged. A generic product is a suitable alternative to both physicians and patients in the management of the disease.

This study aimed to evaluate the rate and extent of drug absorption of a generic formulation of valsartan $160 \mathrm{mg}$ tablet (test formulation, manufactured by Hovid Limited, Perak, Malaysia) against that of a reference formulation (Diovan;, manufactured by Novartis Pharmaceutica S.A., Spain) in order to assess bioequivalence.

\section{Methods}

\section{Study protocol}

The study was approved by the Malaysian Medical Research Ethics Committee (MREC), and was conducted in accordance to the Malaysian Good Clinical Practice (GCP) Guideline. Informed consent was obtained from all study participants before commencement of any trial related procedures. Study centres included a clinical facility situated at the Clinical Research Centre, Seberang Jaya Hospital (Penang, Malaysia) and the bioanalytical laboratory at the University Sains Malaysia (Penang, Malaysia).

\section{Participants}

All study participants were recruited at the clinical research centre by GCP-certified investigators, and were deemed eligible to participate in this study. The inclusion criteria were male between the age of 21 to 55 , within $20 \%$ of ideal body weight for height and build according to the Metropolitan Life Insurance Company Standard, or body mass index between 18.5 to 29.9 , in good health and physical condition as determined by medical history and laboratory test. Laboratory tests conducted included the following: renal function test (serum, creatinine

*Corresponding author: Wen Yao Mak, Clinical Research Centre, Hospital Seberang Jaya, Jalan Tun Hussein Onn, 13700 Perai, Pulau Pinang, Malaysia, Tel: 04-3827333 Ext 511; Fax: 04-3902192; E-mail: makwy@crc.gov.my

Received April 02, 2015; Accepted May 19, 2015; Published May 26, 2015

Citation: Mak WY, Tan SS, Wong JW, Chin SK, Lim AB, et al. (2015) Bioequivalence Study of Two Valsartan $160 \mathrm{mg}$ Formulations: An Open-Label, RandomisedSequence, Single-Dose, Two-Way Crossover Study in Healthy Volunteers under Fasting Conditions. J Bioequiv Availab 7: 179-183. doi:10.4172/jbb.1000235

Copyright: ( 2015 Mak WY, et al. This is an open-access article distributed under the terms of the Creative Commons Attribution License, which permits unrestricted use, distribution, and reproduction in any medium, provided the original author and source are credited. 
, blood, urea and nitrogen), liver function test (total protein, total albumin, total globulin, total bilirubin, serum glutamic oxaloacetic transaminase (SGOT), serum glutamate-pyruvate transaminase (SGPT), full blood count ( heamoglobin, red cell count, haematocrit, total white cell count and platelet), and fasting blood glucose test. All participants had demonstrated ability to read, understand, and sign the informed consent form.

The exclusion criteria included significant clinical deviation from normal as determined by investigators, a history or suspicion of drug dependence and/or alcohol abuse, requirement of tranquilizers, sedatives, chronic medications (for hypertension and diabetes, antiplatelet agents, anti-epileptics, analgesics, opiods, psychotropics, antibiotics, monoamine oxidase inhibitors), a history or presence of organ dysfunction, history or presence of bone-marrow depression, serious blood disorders, cardiac arrhythmias, cardiovascular disease, stroke, bronchospasm, diabetes mellitus, renal diseases, liver diseases, thyrotoxicosis, parkinsonism, benign prostatic hypertrophy, epilepsy or migraine, and malignancy. Volunteers were excluded if they had hypersensitivity to valsartan or any other angiotensin II antagonists, participated in any bioequivalence study or donated blood for the past 8 weeks, who were heavy smokers (more than 10 cigarettes a day), or unable to understand and/or comply to the study protocol or to give consent.

Vital signs of all participants were taken during screening and throughout the study period. These included blood pressure, heart rate, respiratory rate, and body temperature taken in sitting position.

\section{Study design}

The study was an open-label, randomized-sequence, single-dose, two-way crossover study in healthy volunteers under fasting conditions. In accordance to FDA Guidance for Industry: Bioavailability and Bioequivalence Studies for Orally Administered Drug Products General Considerations [7], it was recommended that bioequivalence studies for immediate-release products should be conducted under fasting conditions. Similarly, for EMA Guideline on the Investigation of Bioequivalence [8], it was also recommended to conduct bioequivalence studies under fasting conditions when the Summary of Product Characteristics of Valsartan recommended administration of the medicine irrespective of food intake.

The participants were divided into two groups where the first group received the test formulation during phase I of the study and the reference formulation during phase II. Second group of participants received the reverse order of test/reference formulation. There was a minimum 7 days washout period between the two phases of the study. To maintain consistency of the formulation, both test and reference formulations were taken from the same manufacturing batch (test formulation: batch number BE05598, expiry date: May 2017; reference formulation: batch number B8324, expiry date: September 2014). The excipients used to formulate the test products were general excipients used in tablet formulation, which included fillers, binders, disintegrant and lubricant, in similar quantity and quality to that of the reference products. There was no expected interaction with the pharmacokinetic of the active substance.

The clinical study was initiated on the $24^{\text {th }}$ May 2014 and completed on $1^{\text {st }}$ June 2014. Subsequent analysis of plasma samples, statistical analysis and report preparation were completed on the $4^{\text {th }}$ July 2014.

All participants were confined in the clinical facility and were required to undergo a 10 -hour fasting prior to dosing. One dose of either the test or reference formulation was administered by a qualified pharmacist with $240 \mathrm{ml}$ of plain water. Participants were not allowed any water for 1 hour before and 1 hour after dosing, except the water used for drug administration. Food was withheld for at least 4 hours post dosing. Standardized, calorie-counted meals were provided at 4 and 10 hours after dosing, while standardized snacks were provided at 8 and 13 hour post dosing. Based on the $\mathrm{T}_{\max }$ and $\mathrm{t}_{1 / 2}$ of valsartan, the blood samples were collected at 0 (predose), $0.5,1,1.5,2,2.5,3,4,5$, $6,8,10,12,16$ and 24 hours after drug administration. 5\% deviation from the scheduled blood sampling time was allowed before being considered as protocol deviation.

A total volume of $157 \mathrm{ml}$ of blood $(75 \mathrm{ml}$ during each phase, and $7 \mathrm{ml}$ for blood chemistry analysis) were taken from each participants. The collected blood samples were subsequently centrifuged at 3500 rpm for 15 minutes. Plasma samples were transferred to separate glass containers where they were kept frozen at $-20^{\circ} \mathrm{C}$ until analysis.

The sample size of participants was estimated by using the intrasubject coefficient of variation (CV) [9]. However due to the lack of data on intrasubject $\mathrm{CV}$ of valsartan, the number of required participants was estimated from previous bioequivalence studies as well as the bioavailability of valsartan. A recent study by Sioufi et al. which investigated the effect of age on valsartan pharmacokinetic reported a high coefficient of variation, ranging from $41-66 \%$ [10]. In addition, valsartan had low absolute bioavailability of approximately $25 \%$ [11] which may result in high intersubject variability. It was estimated that the study conducted with 24 participants would be able to achieve a statistical power of at least $80 \%$, assuming the $\mu \mathrm{T} / \mu \mathrm{R}$ would not deviate by more than $5 \%$ and the CV would not exceed $20 \%$.

\section{Randomization and blinding}

The participants were randomised into the test and reference group by using the randomisation program named Random Allocation Software developed by Sagnaei (2004).

The study was an open-label trial, where the investigators and participants knew the type of the formulations administered at each study phase. However, the randomisation list was not available to the bioanalytical team at the University Sains Malaysia until the analysis was completed.

\section{Drug analysis}

High performanceliquid chromatography (HPLC) with Florescence Detector were used to analyse the plasma valsartan concentration. The system comprised of a Waters 600E Multisolvent Delivery System (Waters, Maple Street Milford, USA), a Waters 717 Plus Autosampler (Waters, Maple Street Milford, USA), and a Waters 2475 Multi $\lambda$ Fluorescene Detector (Waters, Maple Street Milford, USA). Data acquisition and analysis were performed with EmpowerTM2 software (Waters, Maple Street Milford, USA).

The separation was performed on a Genesis $\mathrm{C}_{18}$ analytical column $(150 \times 4.6 \mathrm{~mm}, 4 \mu \mathrm{m}$; Grace Davison Discovery Sciences, Illinios, USA), with refillable guard column $(2 \mathrm{~mm} \times 2 \mathrm{~mm}$; Upchurch Scientific, Oak Harbor, USA) packed with Perisorb RP-18 (30-40 $\mu$ m, pellicular). The column was maintained at $23^{\circ} \mathrm{C}$. The mobile phase was a mixture of $50.0 \%$ acetonitrile in $0.01 \mathrm{M}$ disodium hydrogen phosphate buffer, adjusted to $\mathrm{pH} 3.5$ with $85 \%$ phosphoric acid. The chromatographic separation was performed isocratically with a flow rate of $1.0 \mathrm{ml} / \mathrm{min}$. The fluorescence detector was operated at excitation wavelength of $234 \mathrm{~nm}$ and emission wavelength of $374 \mathrm{~nm}$, with sensitivity set at 10000 
Citation: Mak WY, Tan SS, Wong JW, Chin SK, Lim AB, et al. (2015) Bioequivalence Study of Two Valsartan 160 mg Formulations: An Open-Label, Randomised-Sequence, Single-Dose, Two-Way Crossover Study in Healthy Volunteers under Fasting Conditions. J Bioequiv Availab 7 : 179-183. doi:10.4172/jbb.1000235

EUFS. Injection volume was $20 \mathrm{ml}$ and samples were quantified using peak area.

\section{Tolerability}

Vital signs, i.e. blood pressure, pulse rate, respiratory rate and temperature were measured at pre-dose and $4 \mathrm{~h}, 10 \mathrm{~h}$, and $24 \mathrm{~h}$ postdose. Subjects were asked to report any discomfort or adverse events at any time during the study period and at discharge.

\section{Pharmacokinetic analysis}

The pharmacokinetic analysis of valsartan involved the interpretation derivation of several parametres, namely, maximum plasma concentration $\left(\mathrm{C}_{\max }\right)$, time to reach maximum plasma concentration $\left(\mathrm{T}_{\max }\right)$, area under the plasma concentration-time curve from time zero to the last measurable concentration $\left(\mathrm{AUC}_{0-\mathrm{t}}\right)$ and the total area under the plasma concentration-time curve $\left(\mathrm{AUC}_{0-\infty}\right)$. These parametres were derived from the plasma concentration-time data. $\mathrm{C}_{\max }$ and $T_{\max }$ were obtained directly from the plasma values, while $\mathrm{AUC}_{0-\mathrm{t}}$ was calculated using the trapezoidal formula and $\mathrm{AUC}_{\mathrm{t}-\infty}$ was obtained by dividing the last measurable plasma drug concentration with the elimination rate constant $\left(\mathrm{k}_{\mathrm{e}}\right)$. $\mathrm{AUC}_{0-\infty}$ was obtained by summing both values of $\mathrm{AUC}_{0-\mathrm{t}}$ and $\mathrm{AUC}_{\mathrm{t}-\infty}$

The elimination rate constant, $\mathrm{k}$, was derived from the terminal slope of the individual, logarithmic (ln) transformed, plasma concentration values (at least three concentration values were used) and the application of linear regression. The half-life of valsartan $\left(\mathrm{t}_{1 / 2}\right)$ was calculated with the following equation: $\mathrm{t}_{1 / 2}=\ln 2 / \mathrm{k}_{\mathrm{e}}[12]$.

\section{Statistical analysis}

Commercial statistical software, EquivTestPK, was used to perform analysis of the pharmacokinetic parametre (Statistical Solution, Cork, Ireland). Analysis of variance (ANOVA) was used to analyse $\mathrm{C}_{\max }$, $\mathrm{AUC}_{0-\mathrm{t}}, \mathrm{AUC}_{0-\infty}$ and $\mathrm{k}_{\mathrm{e}}$ because it can distinguish the effects due to participants, periods, and treatment [13]. Wilcoxon Signed Rank Test for paired samples was used for analysis of $\mathrm{T}_{\text {max }}$.

Bioequivalence was assessed based on the ratio of the $\mathrm{C}_{\max }, \mathrm{AUC}_{0-\mathrm{t}}$, and $\mathrm{AUC}_{0-\infty}$ values of test-versus-reference formulation. The $90 \%$ confidence intervals were calculated using the two one-sided test procedure where $\alpha=5 \%$ level of significance [14]. The $90 \%$ confidence interval of the ratio of $\mathrm{C}_{\max }, \mathrm{AUC}_{0-\mathrm{t}}$ and $\mathrm{AUC}_{\mathrm{t}-\infty}$ should fall between 80.00-125.00\% (transformed values) [8]. The Malaysian Guideline for Conduct of Bioavailability and Bioequivalence Studies stipulated a similar range for $\mathrm{AUC}_{0-\mathrm{t}}$ and $\mathrm{AUC}_{\mathrm{t}-\infty}$, but allow a wider range for $\mathrm{C}_{\max }$ when it was appropriately justified [15]

\section{Results}

\section{Study participants}

The demographic characteristics of study participants were evaluated as shown in Table 1.

All 24 participants successfully completed both phases of the study and plasma samples were used for pharmacokinetic analysis. A total of two minor protocol deviations were observed: (1) minor delay of more than $5 \%$ in the blood sampling time for subject S6 at 0.5 hour during phase I (2) omission of blood sampling for subject S23 at 5 hour during phase I. For the first deviation, the actual sampling time was used for the calculation of pharmacokinetic parameter and for the second deviation, the $\mathrm{AUC}_{4 \mathrm{~h}-6 \mathrm{~h}}$ was calculated using the trapezoidal formula with the plasma concentration obtained from 4 hour to 6 hour. All deviation were deemed unlikely to adversely affect the study results and conclusion of the study. There was no deviation during the bioanalysis procedure. No serious adverse drug reaction or side effects were reported by the participants nor observed by investigators during the study periods.

\section{Pharmacokinetic and bioequivalence analysis}

Mean plasma valsartan concentration versus time profile for both test and reference formulation were shown in Figure 1; the pharmacokinetic parameter were listed in Table 2.

Both formulations displayed similar concentration-time profile with comparable $\mathrm{T}_{\max }$ and $\mathrm{C}_{\text {max }}$, when both profiles were superimposed. No statistical difference was observed between the logarithmic transformed values of $\mathrm{AUC}_{0-\mathrm{t}}(\mathrm{p}=0.9488), \mathrm{AUC}_{0-\infty}(\mathrm{p}=0.7863)$ and $\mathrm{C}_{\max }$ $(p=0.4695)$ when analysed with ANOVA procedure appropriate for the study design. For parameter $\mathrm{T}_{\max }$, no statistically significant difference was observed as well $(\mathrm{p}=0.5781)$.

The $90 \%$ confidence interval of the ratio of test over reference formulation for $\mathrm{AUC}_{0-\mathrm{t}}, \mathrm{AUC}_{0-\infty}$ and $\mathrm{C}_{\max }$ were 0.9089-1.1778, 0.92381.1819, and $0.9590-1.2436$ respectively, which were within the acceptable bioequivalence limit of 0.8000-1.2500.

\section{Analysis of plasma valsartan concentration}

The analysts who performed the analysis were blinded to the treatment randomisation, and all analysis were performed under Good Laboratory Practice environment. Plasma samples were pre-treated with the following procedure prior to analysis: frozen plasma samples were thawed at room temperature. $250 \mathrm{ml}$ aliquot of the plasma was measure accurately into a $1.5 \mathrm{ml}$ micro centrifuge tube, with the addition of $500 \mu \mathrm{l}$ of acetonitrile. The mixture was then vortex-mixed for 30 seconds, then subjected to centrifugation for 10 minutes at $12800 \mathrm{~g}$. Another $10 \mu \mathrm{l}$ of $70-72 \%$ perchloric acid was then added into the mixture, and the mixture was vortex-mixed for 15 seconds. After that the mixture was centrifuged for 5 minutes at $12800 \mathrm{~g}$. $20 \mu \mathrm{l}$ of the supernatant layer was then injected into the column.

The analytical method was validated in accordance to the US FDA guidance for industry on bioanalytical method validation [16] The parametres assessed were (1) selectivity (2) linearity and range of calibration curve (3) accuracy, precision and recovery and (4) stability of analyte. The method was selective and had linearity over the concentration range of 100.0-7500.0 ng/ml (correlation of coefficient, $r \geq 0.9998$ ). Accuracy was expressed as the percentage of measured

\begin{tabular}{|l|c|}
\hline Characteristic & Value $(n=24)$ \\
\hline Age, $\mathrm{y}$ & 27 \\
Median & 9.0 \\
\hline Interquartile Range & \\
\hline Race, no. (\%) & $22(91.6)$ \\
Malay & $1(4.2)$ \\
Indian & $1(4.2)$ \\
\hline Other & \\
\hline Height, cm & 169 \\
Median & 8.5 \\
\hline Interquartile Range & \\
\hline Weight, kg & 70 \\
Median & 18.0 \\
\hline Interquartile Range & \\
\hline Body mass index, $\mathrm{kg} / \mathrm{m}^{2}$ & 24 \\
Median & 7.2 \\
\hline Interquartile & \\
\hline
\end{tabular}

Table 1: Baseline demographic characteristic of 24 volunteers. 
Citation: Mak WY, Tan SS, Wong JW, Chin SK, Lim AB, et al. (2015) Bioequivalence Study of Two Valsartan 160 mg Formulations: An Open-Label, Randomised-Sequence, Single-Dose, Two-Way Crossover Study in Healthy Volunteers under Fasting Conditions. J Bioequiv Availab 7 : 179-183. doi:10.4172/jbb.1000235

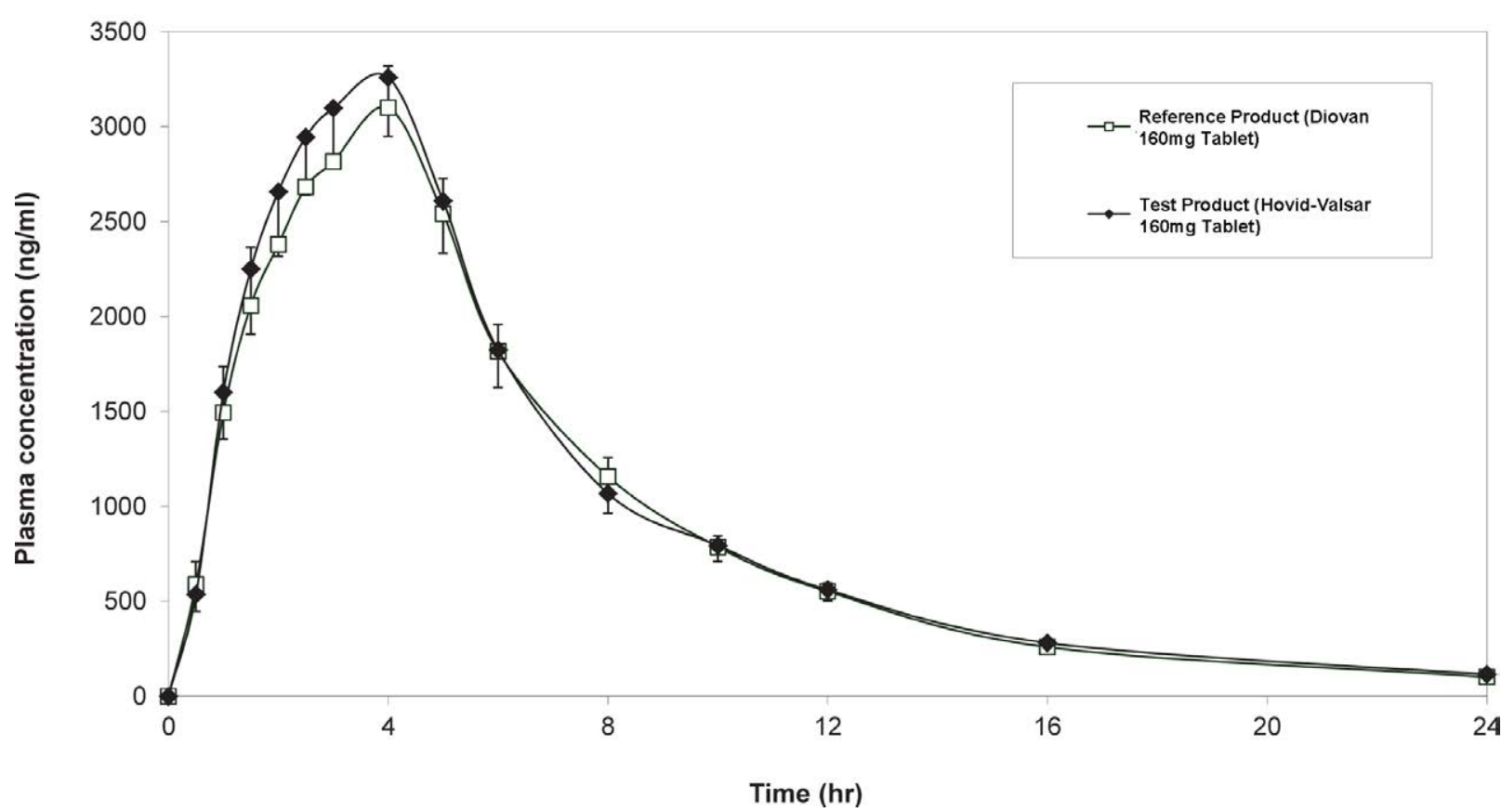

Figure 1: Linear Plots of mean [SEM] plasma valsartan concentration versus time of both test [Havoid-Valsar $160 \mathrm{mg}$ tablet, Hovid Ltd, Ipoh, Malaysia] and reference [Diovan ${ }^{\circledR} 160 \mathrm{mg}$ tablet, Novartis Farmaceutica S.A., Spain] products after oral administration under fasting condition in healthy volunteers [n $\left.=24\right]$.

\begin{tabular}{|c|c|c|}
\hline Pharmacokinetic Parametre & Test Formulation & Reference Formulation \\
\hline $\begin{array}{c}\mathrm{AUC}_{0 \mathrm{t}}, \mathrm{ng} \cdot \mathrm{h} / \mathrm{ml} \\
\text { Mean }(\mathrm{SD})\end{array}$ & 23180 (9969.7) & $22318(7715.6)$ \\
\hline $\begin{array}{c}\mathrm{AUC}_{0-\infty}, \mathrm{ng} \cdot \mathrm{h} / \mathrm{ml} \\
\text { Mean (SD) }\end{array}$ & $24756(10486.6)$ & $23608(8187.5)$ \\
\hline $\begin{array}{l}C_{\max }, \mathrm{ng} / \mathrm{ml} \\
\text { Mean (SD) }\end{array}$ & $3911(1637.1)$ & $3567(1259.0)$ \\
\hline $\begin{array}{c}\mathrm{T}_{\max } \\
\operatorname{Mean}(\mathrm{SD})\end{array}$ & $3.08(1.007)$ & $3.21(1.343)$ \\
\hline $\begin{array}{c}\mathrm{K}_{\mathrm{e}}, \mathrm{hr}^{-1} \\
\text { Mean (SD) }\end{array}$ & $0.13(0.045)$ & $0.15(0.052)$ \\
\hline $\begin{array}{c}t_{1 / 2} \\
\operatorname{Mean}(S D)\end{array}$ & $5.71(1.819)$ & $5.11(1.689)$ \\
\hline
\end{tabular}

$\mathrm{SD}$, standard deviation, $\mathrm{AUC}_{0-\mathrm{t}}$, area under the plasma-concentration curve from dosing to last quantifiable time point; AUC $\mathrm{A}_{0-\infty}$, area under the plasma-concentration curve from dosing to infinity; $\mathrm{C}_{\max }$, peak plasma concentration; $\mathrm{T}_{\max }$, time to reach peak plasma concentration; $\mathrm{k}_{\mathrm{e}}$, elimination rate constant; $\mathrm{t}_{1 / 2}$, half-life

Table 2: Pharmacokinetic parametres of the test valsartan formulation versus the reference formulation after ingestion of one $160 \mathrm{mg}$ tablet under fasting condition.

concentration over that of the spiked value, and precision was denoted using coefficient of variation. For within-day validation, both the mean measured concentration and coefficient of variation did not exceed $15 \%$ for all concentration, and did not exceed $20 \%$ at LLOQ. The accuracy for within-day validation did not deviate by more than $\pm 6.5 \%$, and at LLOQ deviated by $17.3 \%$; for between-day validation, mean measured concentration did not deviate more than $\pm 4.8 \%$, and at LLOQ only deviated by $14.9 \%$. The coefficient of variation values were not more than $1.3 \%$ for all concentration for within-day validation, and not more than $4.2 \%$ for between-day validation. The limit of quantification was set at $100.0 \mathrm{ng} / \mathrm{ml}$. The absolute recovery of valsartan ranged from 87.6$97.7 \%$.

\section{Tolerability analysis}

There were no reported or observed adverse reactions throughout the study period.

\section{Discussion}

The study was designed and conducted in accordance to the European Medicines Agency Guideline on the Investigation of Bioequivalence and the Malaysian Guidelines for the Conduct of Bioavailability and Bioequivalence Studies. According to the guidelines, the design of the current study was fit for the purpose to distinguish the formulation effect from other effects [8]. Previous literature reports of valsartan half-life varied from approximately 6 hours to 11 hours $[3,17,18]$, which correlated with the half-life found in this study. This had reinforced that the washout period had adequately separated the two treatment periods to allow the valsartan concentration in all participants to fall below the lower limit of bioanalytical quantification before the second phase of the study (> 28 half-lives). The sampling times were adequate to characterise the plasma concentration-time profile, providing reliable estimation of the rate $\left(\mathrm{T}_{\max }\right.$ and $\left.\mathrm{C}_{\max }\right)$ and extent of valsartan absorption $\left(\mathrm{AUC}_{0-\mathrm{t}}\right.$ covered at least $80 \%$ of $\mathrm{AUC}_{0-\infty}$ ). 
Citation: Mak WY, Tan SS, Wong JW, Chin SK, Lim AB, et al. (2015) Bioequivalence Study of Two Valsartan 160 mg Formulations: An Open-Label, Randomised-Sequence, Single-Dose, Two-Way Crossover Study in Healthy Volunteers under Fasting Conditions. J Bioequiv Availab 7 : 179-183. doi:10.4172/jbb.1000235

High variability was reported in previous valsartan studies $[17,19,20]$. In this study the intra-subject variation for $\mathrm{AUC}_{0-\mathrm{t}}, \mathrm{AUC}_{0}$ and $\mathrm{C}_{\max }$ were calculated as $29.7 \%, 27.5 \%$ and $33.2 \%$ respectively. A total of 24 subjects who participated in the study was sufficient to provide a power of approximately $70 \%$ for concluding that these two formulations are equivalent at a type 1 error rate of 0.05 , if the true difference is equal or less than $20 \%$ [9].

The sample size of the study was deemed insufficient to generate $>80 \%$ power. However this power refers to the manufacturer's risk of erroneously concluding bioequivalence when the two formulations were indeed bioequivalent. The consumer's risk of erroneously accepting bioequivalence remained unchanged at 5\% level (type I error) [9].

\section{Conclusion}

This study had concluded that the test formulation is bioequivalent to the reference formulation, and had met the Malaysian regulatory definition of bioequivalence based on the rate and extent of absorption of a single dose administered under fasting condition.

\section{Acknowledgement}

The authors thank all medical staffs at Clinical Research Centre, Hospital Seberang Jaya who contributed to the study.

\section{Declaration of Personal Interest}

Kah Hay Yuen was the advisor to the R\&D department of Hovid Ltd, the manufacturer of the test formulation. Siew Siew Tan, Jia Woei Wong, Siaw Kuen Chin, Ai Boey Lim and Ean Peng Soon were employees to Hovid-Research Sdn Bdn, an independent research company which was affiliated with Hovid Ltd. Wen Yao Mak and Irene Looi did not have any conflict of interest to disclose.

\section{Declaration of Funding Interest}

This study was supported by Hovid Ltd.

\section{Reference}

1. Bissessor N, White $\mathrm{H}$ (2007) Valsartan in the treatment of heart failure or left ventricular dysfunction after myocardial infarction. Vasc Health Risk Manag 3 : $425-430$.

2. Antman EM, Anbe DT, Armstrong PW, Bates ER, Green LA, et al. (2004) ACC/ AHA Guidelines for the management of patients with ST-elevation myocardial infarction - executive summary. J Am Coll Cardiol 44: 671-719.

3. Burnier M (2001) Angiotensin II type 1 receptor blockers. Circulation 103: 904 912

4. Michel MC, Foster C, Brunner HR, Liu L (2013) A systematic comparison of the properties of clinically used angiotensin II type 1 receptor antagonists. Pharmacol Rev 65: 809-848.

5. Working Group on Hypertension CPG 2013 (Malaysia). Clinical practice guideline: management of hypertension. [Internet]. Putrajaya: Ministry of Health (Malaysia); 2013 [cited 2015 February 2]. Available from http://www.moh.gov. my/attachments/CPG_Management_of_Hypertension_4th_Edition.pdf

6. Alefan Q, Irahim MIM, Razak TA, Ayub A (2009) Cost of treating hypertension in Malaysia. Asian J Pharm Clin Res 2: 1-5

7. U.S. Department of Health and Human Services, Food and Drug Administration Center for Drug Evaluation and Research (CDER). Guidance for Industry: Bioavailability and Bioequivalence Studies for Orally Administered Drug
Products - General Considerations [Internet]. Silver Spring (MD); U.S. Food and Drug Administration; 2003

8. Committee for Medicinal Products for Human Use (CHMP). Guidelines on the investigation of bioequivalence [Internet]. London: European Medicines Agency; 2010.

9. Diletti E, Hauschke D, Steinijans VW (1992) Sample size determination for bioequivalence assessment by means of confidence intervals. Int $\mathrm{J}$ Clin Pharmacol Ther Toxicol 30 Suppl 1: S51-58.

10. Sioufi A, Marfil F, Jaouen A, Cardot JM, Godbillon J, et al. (1998) The effect of age on the pharmacokinetics of valsartan. Biopharm Drug Dispos 19: 237-244.

11. Criscione L, Bradley WA, Bühlmayer P, Whitebread S, Glazer R, et al. (1995) Valsartan: Preclinical and clinical profile of an antihypertensive angiotensin-II antagonist. Cardiovasc Drug Rev 13: 230-250.

12. Gibaldi M, Perrier D (1992) Pharmacokinetics. $2^{\text {nd }}$ (Edn), Marcel Dekker, New York.

13. Wagner JG (1975) Fundamentals of clinical pharmacokinetics. $1^{\text {st }}$ (Edn), Drug Intelligence Pubns, Illinois.

14. Schuirmann DJ (1987) A comparison of the two one-sided tests procedure and the power approach for assessing the equivalence of average bioavailability. $J$ Pharmacokinet Biopharm 15: 657-680.

15. Committee for Bioequivalence Studies. Malaysian guidelines for the conduct of bioavailability and bioequivalence studies [Internet]. Kuala Lumpur: Ministry of Health; 2000.

16. U.S. Department of Health and Human Services, Food and Drug Administration Center for Drug Evaluation and Research (CDER). Guidance for Industry: Bioanalytical Method Validation [Internet]. Silver Spring (MD): U.S. Food and Drug Administration; 2001

17. Spínola ACF, Almeida S, Filipe A, Neves R, Trabelsi F, et al. (2009) Results of a single-center, single-dose, randomized-sequence, open-label, two-way crossover bioequivalence study of two formulations of valsartan $160-\mathrm{mg}$ tablets in healthy volunteers under fasting conditions. Clin Ther 31: 1992-2001.

18. Flesch G, Müller P, Lloyd P (1997) Absolute bioavailability and pharmacokinetics of valsartan, an angiotensin II receptor antagonist, in man. Eur J Clin Pharmaco 52: $115-120$

19. Iqbal M, Khuroo A, Batolar LS, Tandon M, Monif T, et al. (2010) Pharmacokinetic and bioequivalence study of three oral formulations of valsartan $160 \mathrm{mg}$ : a single-dose, randomized, open-label, three-period crossover comparison in healthy Indian male volunteers. Clin Ther 32: 588-596.

20. Se'chaud R, Graf P, Bigler H, Gruendl E, Letzkus M, et al. (2002) Bioequivalence study of a valsartan tablet and a capsule formulation after single dosing in healthy volunteers using a replicated crossover design. Int J Clin Pharmaco Ther 40: 35-40. 